\title{
In Vitro Free Radical Scavenging Activity of a Wild Edible Mushroom, Sparassis crispa (Wulf.) Fr., from North Western Himalayas, India
}

\author{
Madhavi Joshi and Anand Sagar \\ Department of Bio-Sciences, Himachal Pradesh University, Shimla 171005, India \\ Correspondence should be addressed to Madhavi Joshi; madhavi.joshi1986@gmail.com
}

Received 20 June 2014; Accepted 4 August 2014; Published 13 August 2014

Academic Editor: Ángel Domínguez

Copyright ( $\odot 2014$ M. Joshi and A. Sagar. This is an open access article distributed under the Creative Commons Attribution License, which permits unrestricted use, distribution, and reproduction in any medium, provided the original work is properly cited.

\begin{abstract}
Bioactive compounds and antioxidant activity of methanolic extract of Sparassis crispa collected from North Western Himalayan region of India were analyzed. Phenolic content $11.14 \pm 0.08 \mathrm{mg}$ tannic acid equivalent per $\mathrm{g}$ of the extract and flavonoids $1.96 \pm$ $04 \mathrm{mg}$ catechin equivalent per $\mathrm{g}$ of the extract were recorded to be the major antioxidant components in this wild edible mushroom. Significant antioxidant efficiency on inhibition of 2,2-diphenyl-1-picrylhydrazyl (DPPH) was observed when compared to standard antioxidant like L-ascorbic acid. $\mathrm{IC}_{50}$ value of the extract was $2.11 \mathrm{mg} / \mathrm{mL}$. The findings suggest $S$. crispa as an easily accessible source of natural antioxidants.
\end{abstract}

\section{Introduction}

Oxidation is essential in many living organisms for the production of energy to fuel biological processes. However, uncontrolled production of oxygen derived free radicals results in the onset of many diseases, such as cancer, rheumatoid arthritis, and atherosclerosis, as well as in degenerative processes associated with ageing [1]. Almost all organisms are well protected against free radical damage by antioxidant enzymes such as superoxide dismutase (SOD) and catalase or chemical compounds such as ascorbic acid, $\alpha$-tocopherols, carotenoids, polyphenol compounds, and glutathione [2]. As improved antioxidant status helps to minimize the oxidative damage and thus delay or prevent pathological changes. Potential antioxidant therapy should be, therefore, included either as natural free radical scavenging antioxidant enzymes or as an agent which is capable of augmenting the activity of antioxidant enzymes [3].

Traditionally, wild edible mushrooms are used by most of the Asian and other countries worldwide as food and medicinal sources $[4,5]$. They are also a good source of antioxidants. In the past few years, the suspected toxicity of some of the synthetic compounds used in food has raised interest in natural products; therefore, compounds from natural sources that possess antioxidant activity are being sought. Naturally occurring substances having antioxidant property are becoming one of the most appealing modes of modern therapy. Among them, mushrooms or their derivatives or extracts occupy an elite position to perform this function [6-11].

Mushrooms are gaining importance both as nutrient supplement and disease curing medicine. Mushrooms are unlimited source of therapeutically useful and biologically active agents. Compounds of mushrooms have been reported to have antifungal, anti-inflammatory, antibacterial, antiviral, antitumor, hepatoprotective, antidiabetic, antithrombotic, hypotensive, and antioxidant capacity [12-14].

North Western Himalayan region of India has been known as a belt containing rich varieties of wild mushrooms including Sparassis crispa, a well-known edible mushroom. S. crispa has been collected, worked out, and identified by earlier workers [15]. However, antioxidant properties of fruiting bodies of this mushroom from North Western Himalayan region have not been reported. In the present study, antioxidant properties of Sparassis crispa have been reported. The contents of potential antioxidant components like phenols, flavonoids, ascorbic acid, $\beta$-carotene, and lycopene have also been estimated. 


\section{Materials and Methods}

2.1. Standards and Reagents. DPPH (2,2-diphenyl-1-picrylhydrazyl), L-ascorbic acid, tannic acid, (+)catechin, and folin ciocalteu reagent were obtained from Sigma (St. Louis, MO, USA). All other chemicals and solvents were of analytical grade.

2.2. Sample Collection and Extract Preparation. Fruiting bodies of S. crispa, an edible wild mushroom, were collected from Potter's Hill forest of North Western Himalayas, India, and identified at Department of Biosciences, H.P.U., Shimla (Figure 1). Fresh fruiting bodies of mushrooms were cut into small pieces and sun-dried. A coarse powder was obtained using a mill. For extraction, $10 \mathrm{~g}$ sample was extracted by stirring at $100 \mathrm{rpm}$ with $100 \mathrm{~mL}$ methanol at $30^{\circ} \mathrm{C}$ for 24 hours and filtered through Whatman number 1 filter paper. The residue was then extracted with two additional $100 \mathrm{~mL}$ portions of methanol, in a similar manner. The combined methanolic extracts were evaporated by rotary evaporator at $40^{\circ} \mathrm{C}$ to dryness, redissolved in methanol to a concentration of $20 \mathrm{mg} / \mathrm{mL}$, and stored in the dark at $4^{\circ} \mathrm{C}$ for further use [16].

2.3. Scavenging Ability on 2,2-Diphenyl-1-picrylhydrazyl Radicals. The hydrogen atoms or electron donation ability of the extracts was measured from the bleaching of the purple coloured DPPH methanolic solution with little modification. $3 \mathrm{~mL}$ of various concentrations of the extracts in methanol was added to $1 \mathrm{~mL}$ of methanolic DPPH (final concentration of DPPH was $200 \mu \mathrm{M}$ ). The mixture was shaken vigorously and allowed to stand for $30 \mathrm{~min}$ at room temperature and absorbance of the resulting solution was measured at $517 \mathrm{~nm}$ using spectrophotometer (Merck Spectroquant Pharo 100) [17]. Inhibition of the DPPH free radicals in (\%) was calculated as

$$
\begin{aligned}
& \text { Inhibition }(\%) \\
& \qquad=\frac{\text { absorbance control }- \text { absorbance sample }}{\text { absorbance control }} \times 100,
\end{aligned}
$$

where, absorbance control is the absorbance of DPPH radical + methanol; absorbance sample is the absorbance of DPPH radical + sample extract/standard.

\subsection{Determination of Antioxidant Components}

2.4.1. Total Phenolic Contents of the Extract Was Determined following Makkar et al. [18]. The reaction mixture was prepared by mixing $0.1 \mathrm{~mL}$ of the extract and $0.9 \mathrm{~mL}$ of double distilled water. $2.5 \mathrm{~mL}$ of sodium carbonate solution (20\%) was added to it, followed by $0.5 \mathrm{~mL}$ of FCR $(1 \mathrm{~N})$. After 40 minutes at room temperature, absorbance was read at $725 \mathrm{~nm}$. Tannic acid $(0.5 \mathrm{mg} / \mathrm{mL})$ was used to prepare standard curve. The results were expressed as mg of TAEs per $g$ of the extracts.

2.4.2. The Amounts of Total Flavonoids (TFC) Were Determined Colorimetrically. A suitable aliquot $250 \mu \mathrm{L}$ taken for estimation [19] was mixed with $1 \mathrm{~mL}$ of water in a test tube. At the start, $75 \mu \mathrm{L}$ of $5 \%$ aqueous $\mathrm{NaNO}_{2}$ was added to

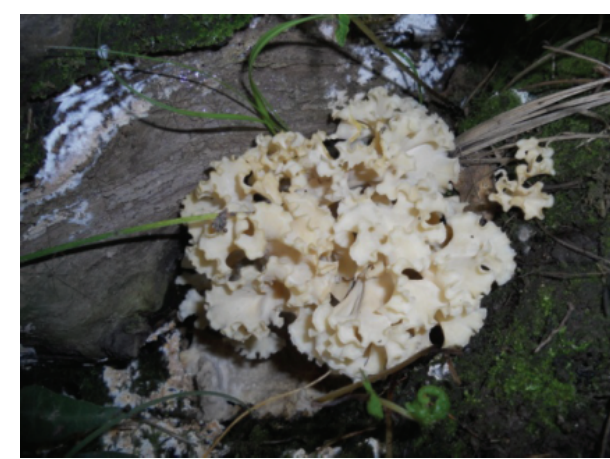

Figure 1: S. crispa in its natural habitat.

the test tube; then after $5 \mathrm{~min} 150 \mu \mathrm{L}$ of $10 \% \mathrm{AlCl}_{3}$ and after $6 \mathrm{~min} 500 \mu \mathrm{L}$ of $1.0 \mathrm{M} \mathrm{NaOH}$ were added sequentially. Finally, $275 \mu \mathrm{L}$ distilled water was added. The reaction mixture was mixed thoroughly. The absorbance was noted at $510 \mathrm{~nm}$ using a spectrophotometer. TFC, calculated using a standard calibration curve, were reported as $(+)$ catechin equivalents (mg CE/g of the extract).

2.4.3. $\beta$-Carotene and Lycopene Were Determined according to the Method of Nagata and Yamashita [20]. The dried extract $(100 \mathrm{mg})$ was vigorously shaken with $10 \mathrm{~mL}$ of acetonehexane mixture $(4: 6)$ for 1 minute and filtered through Whatman number 1 filter paper. The absorbance of the filtrate was measured at 453,505, and $663 \mathrm{~nm}$. The contents of $\beta$-carotene and lycopene were calculated according to the following:

$$
\begin{aligned}
\text { Lycopene }\left(\frac{\mathrm{mg}}{100 \mathrm{~mL}}\right)= & -0.0458 \mathrm{~A}_{663} \\
& +0.372 \mathrm{~A}_{505}+0.0806 \mathrm{~A}_{453} \\
\beta \text {-carotene }\left(\frac{\mathrm{mg}}{100 \mathrm{~mL}}\right)= & 0.216 \mathrm{~A}_{663} \\
& -0.304 \mathrm{~A}_{505}+0.452 \mathrm{~A}_{453} .
\end{aligned}
$$

2.4.4. The Ascorbic Acid Content Was Determined from Dried Methanolic Extract. A $100 \mathrm{mg}$ of the extract was mixed with $1 \%$ metaphosphoric acid $(10 \mathrm{~mL})$ and incubated at room temperature for $45 \mathrm{~min}$ and filtered. $1 \mathrm{~mL}$ of filtrate was mixed with $9 \mathrm{~mL}$ of 2,6-dichloroindophenol and absorbance was recorded at $515 \mathrm{~nm}$ in $30 \mathrm{~min}$ against a blank. The ascorbic acid content was calculated using calibration curve of Lascorbic acid. The results were expressed in terms of $\mathrm{mg}$ of ascorbic acid per $g$ of extract.

2.5. Statistical Analysis. All the analyses were performed in triplicates and results were reported as means \pm standard deviation (SD).

\section{Results and Discussion}

3.1. The Macrofungi Extract Showed Positive Antioxidant Activity by Fading the Violet Colour of DPPH Solution to Yellow and Pale Violet. The scavenging activities of radical 
were in direct proportion with the concentrations of the extract. As the concentration of extract was increased, the scavenging activity towards DPPH radicals was also elevated. The results showing in Figure 2 clearly indicates the increase in \% inhibition of DPPH free radical on increasing concentration. The concentration of antioxidant needed to decrease the initial DPPH concentration by $50 \%\left(\mathrm{IC}_{50}\right)$ is a parameter widely used to measure the antioxidant activity [21].

$\mathrm{IC}_{50}$ value of the selected mushroom extract was $2.11 \mathrm{mg} / \mathrm{mL}$ compared with L-ascorbic acid $\mathrm{IC}_{50}=0.062 \mathrm{mg} / \mathrm{mL}$. The results of DPPH scavenging effect of methanolic extracts were higher than what was reported by Puttaraju et al. [22]. DPPH assay is a widely used method to evaluate antioxidant activities in a relatively short time compared to other methods [23]. It has the advantage of being unaffected by certain side reactions which is common in laboratory-generated free radicals such as the hydroxyl and superoxide anion [24].

3.2. Bioactive Components. The present studies also concentrate on five different bioactive components like phenols, flavonoids, ascorbic acid, $\beta$-carotene, and lycopene (Table 1). Phenolic compounds form a major class of phytochemicals, which are responsible for inhibiting the oxidative damage caused by free radicals generated inside of our body [25]. Total phenolic content in the methanolic extract was found to be $11.14 \mathrm{mg}$ tannic acid equivalent per $\mathrm{g}$ of the extract. The total phenolic content in methanolic extracts of $S$. crispa clearly demonstrates that it can be considered as a better source of polyphenols. The key role of phenolic compounds as scavengers of free radicals is emphasised in several reports [26-28], and these compounds seem to be associated with antioxidant activity $[29,30]$.

Flavonoids are well-known dietary biochemical agents, which show $\mathrm{pH}$ dependent antioxidant behaviour in human body. These molecules are also effective for cardiovascular system and work as cardioprotective agents [31]. The total flavonoid contents in methanolic extracts of wild $S$. crispa were found to be $1.96 \mathrm{mg}$ catechin equivalent per $\mathrm{g}$ of the extract.

Ascorbic acid was found in small amounts $(2.12 \mathrm{mg} / 100 \mathrm{~g})$ and $\beta$-carotene and lycopene were only found in vestigial amounts. Several references are available on insignificant quantities of ascorbic acid, lycopene, and $\beta$-carotene in methanolic extracts of fruiting bodies as naturally occurring antioxidant components $[32,33]$. Though other antioxidants were probably present in this mushroom extract, the amount of ascorbic acid, lycopene, and $\beta$-carotene found was very low, which emphasised the idea that phenolic compounds could make a significant contribution to the mushrooms antioxidant activity.

\section{Conclusion}

The findings from the study can be used to disseminate the information regarding antioxidant properties to the public. The results suggest that the consumption of $S$. crispa may enhance the antioxidant protection system of human body. Comprehensive studies on the antioxidant properties of this

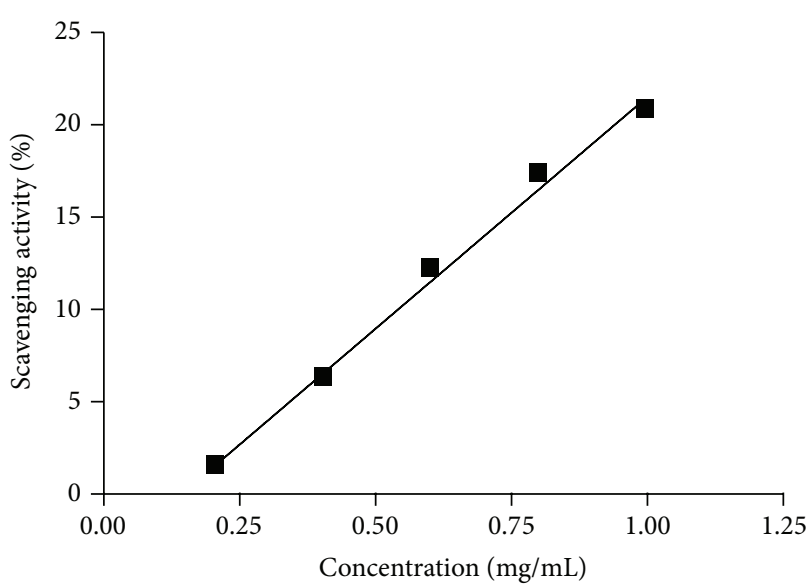

FIgURE 2: Antioxidant activity of $S$. crispa extract using DPPH test. Slope $=25.22 \pm 1.180, Y$-Intercept $=-3.423 \pm 0.7825, r^{2}=0.9935$.

TABLE 1: Contents of total phenols, flavonoids, ascorbic acid, $\beta$ carotene, and lycopene in the mushroom extract.

\begin{tabular}{lc}
\hline \multicolumn{2}{c}{ Mushroom extract of S. crispa } \\
\hline Total phenols $(\mathrm{mg} / \mathrm{g})$ & $11.14 \pm 0.08$ \\
Total flavonoids $(\mathrm{mg} / \mathrm{g})$ & $1.96 \pm 0.040$ \\
Ascorbic acid $(\mathrm{mg} / 100 \mathrm{~g})$ & $2.12 \pm 0.00$ \\
$\beta$-carotene $(\mathrm{mg} / \mathrm{g})$ & $0.121 \pm 0.011$ \\
Lycopene $(\mathrm{mg} / \mathrm{g})$ & $0.066 \pm 0.003$ \\
\hline
\end{tabular}

mushroom are not available, so the findings from this study can act as a baseline reference for further research.

\section{Conflict of Interests}

The authors declare that there is no conflict of interests regarding the publication of this paper.

\section{Acknowledgments}

The authors express their sincere thanks to the Head and Assistant Scientist Biochemistry, Dr. Nageswar Singh, CSKHPKV, Palampur, for providing laboratory facilities. Financial support from UGC (F.17-40/08 SA-1), New Delhi, is also gratefully acknowledged.

\section{References}

[1] B. Halliwell and J. M. C. Gutteridge, Free Radicals in Biology and Medicine, Oxford University Press, Oxford, UK, 1989.

[2] E. Niki, H. Shimaski, and M. Mino, Antioxidantism-Free Radical and Biological Defence, Gakkai Syuppan Centre, Tokyo, Japan, 1994.

[3] A. Bast, G. R. Haenen, and C. J. Doelman, "Oxidants and antioxidants: state of the art," The American Journal of Medicine, vol. 30, pp. 2-13, 1999.

[4] P. Manzi, L. Gambelli, S. Marconi, V. Vivanti, and L. Pizzoferrato, "Nutrients in edible mushrooms: an inter-species 
comparative study," Food Chemistry, vol. 65, no. 4, pp. 477-482, 1999.

[5] R. Sanmee, B. Dell, P. Lumyong, K. Izumori, and S. Lumyong, "Nutritive value of popular wild edible mushrooms from northern Thailand," Food Chemistry, vol. 82, no. 4, pp. 527-532, 2003.

[6] N. Ito, S. Fukushima, and H. Tsuda, "Carcinogenicity and modification of the carcinogenic response by BHA, BHT, and other antioxidants," Critical Reviews in Toxicology, vol. 15, no. 2, pp. 109-150, 1985.

[7] W. L. Stone, I. LeClair, T. Ponder, G. Baggs, and B. B. Reis, "Infants discriminate between natural and synthetic vitamin E," The American Journal of Clinical Nutrition, vol. 77, no. 4, pp. 899-906, 2003.

[8] S. Khatua, S. Paul, and K. Acharya, "Mushroom as the potential source of new generation of antioxidant: a review," Research Journal of Pharmacy and Technology, vol. 6, no. 5, pp. 496-505, 2013.

[9] P. Mitra, S. Khatua, and K. Acharya, "Free radical scavenging and nos activation properties of water soluble crude polysaccharide from Pleurotus ostreatus," Asian Journal of Pharmaceutical and Clinical Research, vol. 6, no. 3, pp. 67-70, 2013.

[10] K. Acharya and M. Rai, "Proximate composition, free radical scavenging and nos activation properties of a wild edible mushroom," International Journal of Pharmacy and Pharmaceutical Sciences, vol. 5, no. 1, pp. 67-72, 2013.

[11] M. Rai and K. Acharya, "Proximate composition, free radical scavenging and NOS activation properties of Ramaria aurea," Research Journal of Pharmacy and Technology, vol. 5, no. 11, pp. 1421-1427, 2012.

[12] S. P. Wasser and A. L. Weis, "Medicinal properties of substances occurring in higher Basidiomycetes mushrooms: current perspective (review)," International Journal of Medicinal Mushrooms, vol. 1, pp. 31-62, 1999.

[13] B. Ribeiro, J. Rangel, P. Valentão, P. Baptista, R. M. Seabra, and P. B. Andrade, "Contents of carboxylic acids and two phenolics and antioxidant activity of dried Portuguese wild edible mushrooms," Journal of Agricultural and Food Chemistry, vol. 54, no. 22, pp. 8530-8537, 2006.

[14] B. Ribeiro, P. Valentão, P. Baptista, R. M. Seabra, and P. B. Andrade, "Phenolic compounds, organic acids profiles and antioxidative properties of beefsteak fungus (Fistulina hepatica)," Food and Chemical Toxicology, vol. 45, no. 10, pp. 18051813, 2007.

[15] A. Sagar and S. Tandon, "Study on ultra structure and antibacterial activity of S. crispa (Wulf.)Fr," Indian Journal of Mushrooms, vol. 30, no. 2, pp. 15-19, 2012.

[16] J. Pal, S. Ganguly, K. S. Tahsin, and K. Acharya, "In vitro free radical scavenging activity of wild edible mushroom, Pleurotus squarrosulus (Mont.) Singer," Indian Journal of Experimental Biology, vol. 47, no. 12, pp. 1210-1218, 2010.

[17] N. Alam, K. N. Yoon, K. R. Lee et al., "Antioxidant activities and tyrosinase inhibitory effects of different extracts from Pleurotus ostreatus fruiting bodies," Mycobiology, vol. 38, pp. 295-301, 2010.

[18] H. P. S. Makkar, M. Blümmel, N. K. Borowy, and K. Becker, "Gravimetric determination of tannins and their correlations with chemical and protein precipitation methods," Journal of the Science of Food and Agriculture, vol. 61, no. 2, pp. 161-165, 1993.

[19] J. Zhishen, T. Mengcheng, and W. Jianming, "The determination of flavonoid contents in mulberry and their scavenging effects on superoxide radicals," Food Chemistry, vol. 64, no. 4, pp. 555559, 1999.
[20] M. Nagata and I. Yamashita, "Simple method for simultaneous determination of chlorophyll and carotenoids in tomato fruit," Nippon Shokuhin Kogyo Gakkaishi, vol. 39, p. 925, 1992.

[21] C. Sanchez-Moreno, J. A. Larrauri, and F. Saura-Calixto, "A procedure to measure the antiradical efficiency of polyphenols," Journal of Agriculture and Food Chemistry, vol. 47, pp. 425-431, 1998.

[22] N. G. Puttaraju, S. U. Venkateshaiah, S. M. Dharmesh, S. M. N. Urs, and R. Somasundaram, "Antioxidant activity of indigenous edible mushrooms," Journal of Agricultural and Food Chemistry, vol. 54, no. 26, pp. 9764-9772, 2006.

[23] M. S. Mokbel and F. Hashinaga, "Evaluation of the antioxidant activity of extracts from buntan (Citrus grandis Osbeck) fruit tissues," Food Chemistry, vol. 94, no. 4, pp. 529-534, 2006.

[24] R. Amarowicz, R. B. Pegg, P. Rahimi-Moghaddam, B. Barl, and J. A. Weil, "Free-radical scavenging capacity and antioxidant activity of selected plant species from the Canadian prairies," Food Chemistry, vol. 84, no. 4, pp. 551-562, 2004.

[25] L. R. Ferguson, "Role of plant polyphenols in genomic stability," Mutation Research, vol. 475, no. 1-2, pp. 89-111, 2001.

[26] A. Rawat, M. Mohsin, P. S. Negi, A. N. Sah, and S. Singh, "Evaluation of polyphenolic contents and antioxidant activity of wildly collected Ganoderma lucidum from central Himalayan hills of India," Asian Journal of Plant Science and Research, vol. 3, no. 3, pp. 85-90, 2013.

[27] H. H. Arbaayah and Y. K. Umi, "Antioxidant properties in the Oyster mushrooms (Pleurotus spp.) and split gill mushroom (Schizophyllum commune) ethanolic extracts," Mycosphere, vol. 4, no. 4, pp. 661-673, 2013.

[28] G. S. Jeena, H. Punetha, O. Prakash, M. Chandra, and K. P. S. Kushwaha, "Study on in vitro antioxidant potential of some cultivated Pleurotus sps (Oyster mushroom)," Indian Journal of Natural Products and resources, vol. 5, no. 1, pp. 56-61, 2014.

[29] N. Gursoy, C. Sarikurkcu, B. Tepe, and M. H. Solak, "Evaluation of antioxidant activities of 3 edible mushrooms: Ramaria flava (Schaef.: Fr.) Quél., Rhizopogon roseolus (Corda) T.M. Fries., and Russula delica Fr," Food Science and Biotechnology, vol. 19, no. 3, pp. 691-696, 2010.

[30] L. Barros, P. Baptista, and I. C. F. R. Ferreira, "Effect of Lactarius piperatus fruiting body maturity stage on antioxidant activity measured by several biochemical assays," Food and Chemical Toxicology, vol. 45, no. 9, pp. 1731-1737, 2007.

[31] S. M. Nabavi, M. A. Ebrahimzadeh, S. F. Nabavi, A. Hamidinia, and A. R. Bekhradnia, "Determination of antioxidant activity, phenol and flavonoid content of Parrotia persica Mey," Pharmacologyonline, vol. 2, pp. 560-567, 2008.

[32] J. L. Mau, H. C. Lin, and S. F. Song, "Antioxidant properties of several speciality mushrooms," Food Research International, vol. 35, no. 6, pp. 519-526, 2002.

[33] L. Barros, M. J. Ferreira, B. Queirós, I. C. F. R. Ferreira, and P. Baptista, "Total phenols, ascorbic acid, $\beta$-carotene and lycopene in Portuguese wild edible mushrooms and their antioxidant activities," Food Chemistry, vol. 103, no. 2, pp. 413-419, 2007. 

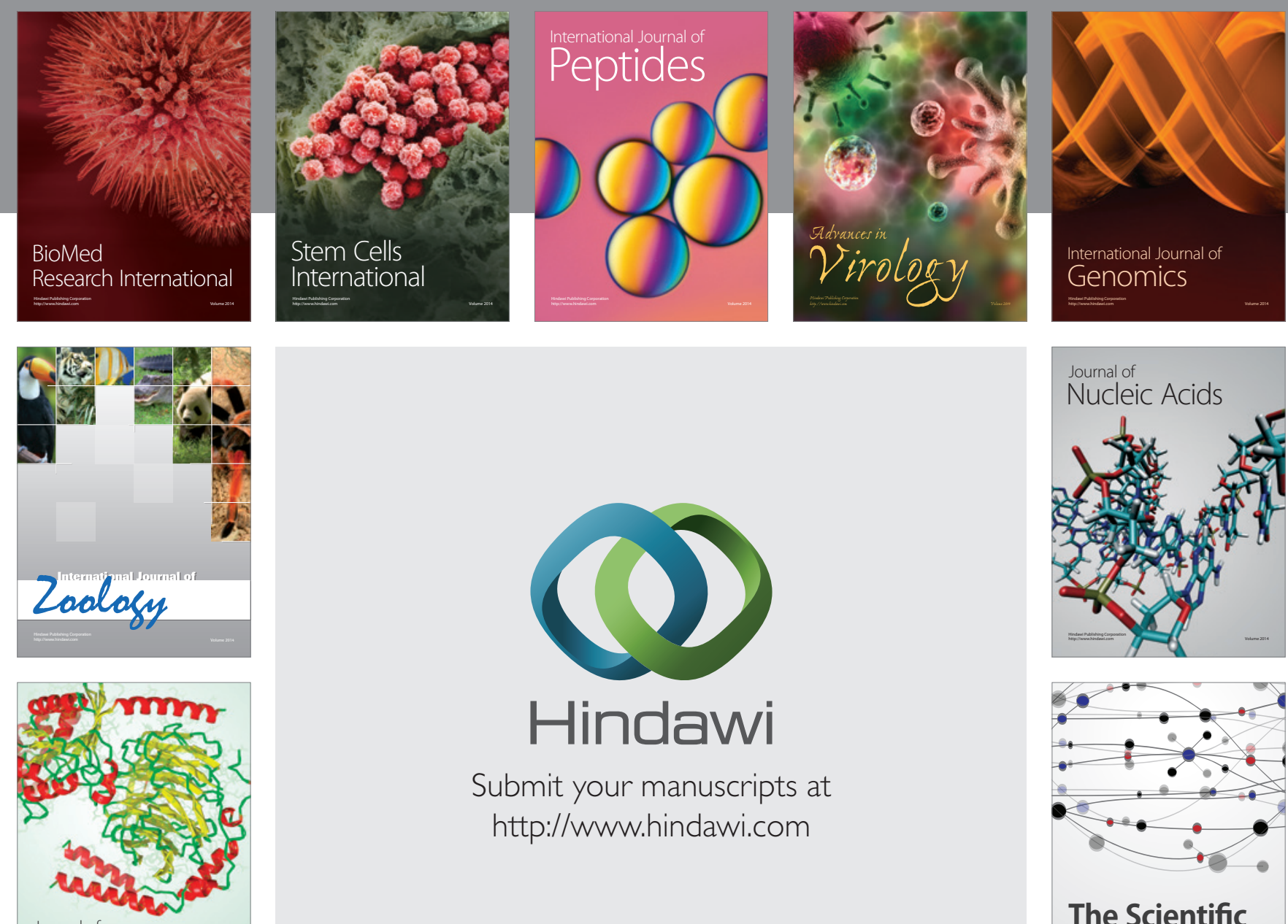

Submit your manuscripts at

http://www.hindawi.com

Journal of
Signal Transduction
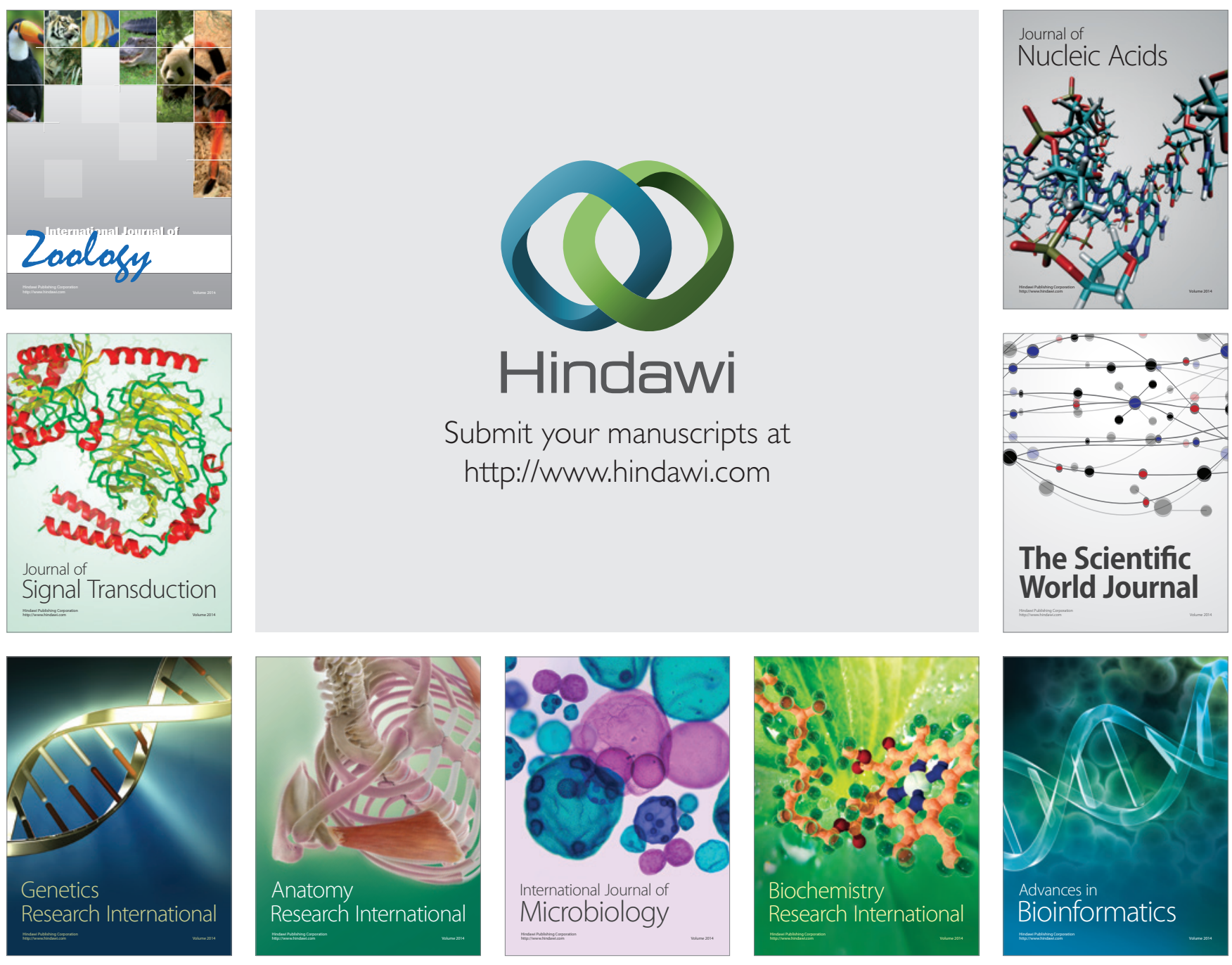

The Scientific World Journal
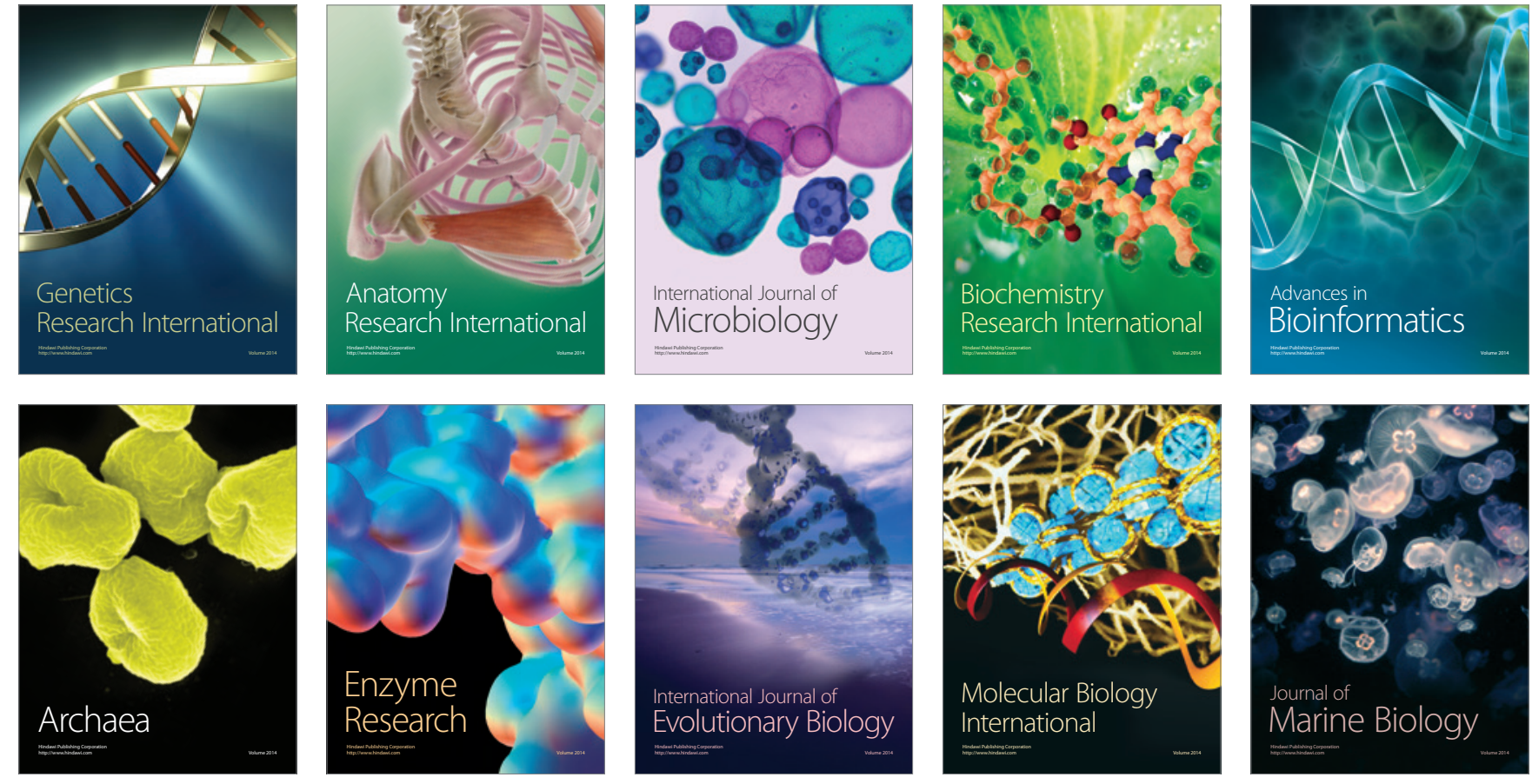